\title{
Lentigo Simplex
}

National Cancer Institute

\section{Source}

National Cancer Institute. Lentigo Simplex. NCI Thesaurus. Code C4070.

The most common form of the skin disorder lentigo, characterized by a single or multiple benign, pigmented macules of unknown etiology that are present at birth or develop in early childhood. 